\title{
Sulfide assimilation by ectosymbionts of the sessile ciliate, Zoothamnium niveum
}

\author{
Hans Røy · Kay Vopel · Markus Huettel • \\ Bo Barker Jørgensen
}

Received: 17 October 2008 / Accepted: 15 December 2008 / Published online: 3 February 2009

(C) The Author(s) 2009. This article is published with open access at Springerlink.com

\begin{abstract}
We investigated the constraints on sulfide uptake by bacterial ectosymbionts on the marine peritrich ciliate Zoothamnium niveum by a combination of experimental and numerical methods. Protists with symbionts were collected on large blocks of mangrove-peat. The blocks were placed in a flow cell with flow adjusted to in situ velocity. The water motion around the colonies was then characterized by particle tracking velocimetry. This shows that the feather-shaped colony of $Z$. niveum generates a unidirectional flow of seawater through the colony with no recirculation. The source of the feeding current was the free-flowing water although the size of the colonies
\end{abstract}

Communicated by M. Kühl.

Electronic supplementary material The online version of this article (doi:10.1007/s00227-008-1117-6) contains supplementary material, which is available to authorized users.

H. Røy · B. B. Jørgensen

Max Planck Institute for Marine Microbiology,

Celsiusstr. 1, 28359 Bremen, Germany

Present Address:

H. Røy ( $\square)$

Department of Biological Sciences,

Center for Geomicrobiology, University of Aarhus,

Ny Munkegade 1535, 8000 Aarhus C, Denmark

e-mail: hans.roy@biology.au.dk

K. Vopel

School of Applied Sciences,

Auckland University of Technology, Mail No C43,

Private Bag 92006, Auckland 1142, New Zealand

M. Huettel

Department of Oceanography,

Florida State University, 117 N Woodward Ave.,

OSB 517, Tallahassee, FL 32306-4320, USA suggests that they live partly submerged in the diffusive boundary layer. We showed that the filtered volume allows $Z$. niveum to assimilate sufficient sulfide to sustain the symbiosis at a few micromoles per liter in ambient concentration. Numerical modeling shows that sulfide oxidizing bacteria on the surfaces of $Z$. niveum can sustain 100-times higher sulfide uptake than bacteria on flat surfaces, such as microbial mats. The study demonstrates that the filter feeding zooids of $Z$. niveum are preadapted to be prime habitats for sulfide oxidizing bacteria due to $Z$. niveum's habitat preference and due to the feeding current. $Z$. niveum is capable of exploiting low concentrations of sulfide in near norm-oxic seawater. This links its otherwise dissimilar habitats and makes it functionally similar to invertebrates with thiotrophic symbionts in filtering organs.

\section{Introduction}

The peritrich ciliate Zoothamnium niveum (Ehrenberg 1838) forms attached contractile colonies that are visible to the naked eye. The colony shape resembles a feather with an average length between 3 and $5 \mathrm{~mm}$. The side-branches of the "feather" carry several hundred microzooids (zooid $=$ single ciliate) in a regular pattern (see BauerNebelsick et al. 1996a, b for a detailed description). The entire surface of the zooids, stalk and branches are covered by a single layer of sulfide-oxidizing bacteria belonging to the Gamma-proteobacteria (Rinke et al. 2007). The peritrich ciliates are filter-feeders, and the microzooids of $Z$. niveum possess a fully developed oral ciliature and cytopharynx, similar to Zoothamnium species that are not covered by sulfide oxidizing bacteria (Bauer-Nebelsick et al. 1996b). Rapid contractions of zooids, branches and the distal parts of the stalk are characteristic of all Zoothamnium 


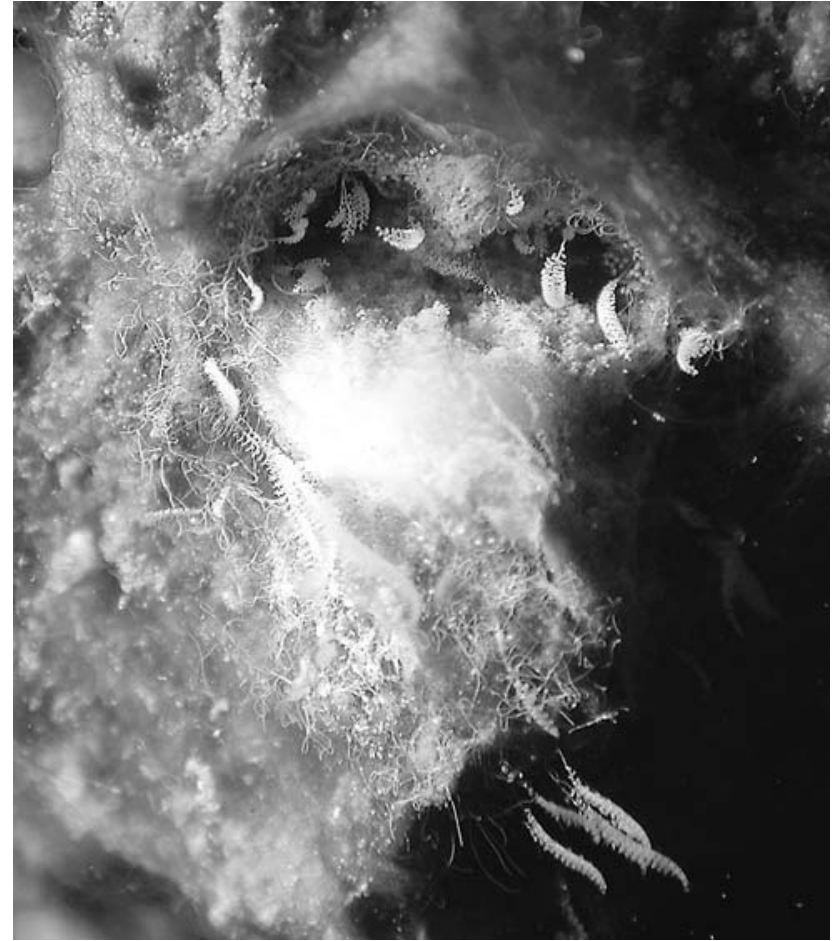

Fig. 1 White spot around a $1 \mathrm{~cm}$ wide conduit into the peat wall. Several Zoothamnium niveum colonies can be seen around the hole. Recorded in situ with a Nikon coolpix 960 in underwater housing

species. For $Z$. niveum, the contraction takes only about $4 \mathrm{~ms}$, and the average velocity reaches $520 \mathrm{~mm} \mathrm{~s}^{-1}$ (Vopel et al. 2002). During contractions and the following slow expansion the cilia cease.

The type organisms for a recent re-description of Z. niveum (Bauer-Nebelsick et al. 1996b) were collected on mangrove islands of the Belize barrier reef. Several ecological investigations have been performed on this population. Aggregations of $Z$. niveum and non-symbiotic sulfur-bacteria form characteristic "white spots" (Fig. 1) on undercut peat-banks under Red Mangrove (Rhizophora mangle) stands. Typical spots are $5-25 \mathrm{~mm}$ in diameter and contain 9-43 Zoothamnium colonies (Ott et al. 1998). The spots often occur around bark-lined holes in the peat. The holes form when a mangrove root dies and the core of the root decomposes. The seawater in these bark conduits is anoxic and contains up to $1 \mathrm{mmol} \mathrm{L}^{-1}$ sulfide. Sulfidic water in the conduits mixes with the surrounding seawater, primarily driven by wave-generated oscillating boundary flow. This makes the holes function like miniature sulfide vents (Vopel et al. 2005).

Though the published evidence is mostly suggestive, the association between $Z$. niveum and its ectosymbionts has been assumed to be obligatory. A trophic character of the symbiosis is suggested from observation of bacteria morphotypes in the food vacuoles (Bauer-Nebelsick et al. 1996b), and by poor growth of the ciliates without ectosymbionts (Ott et al. 1998; Vopel et al. 2001). Ott et al. (1998) proposed that $Z$. niveum supplies the bacterial symbionts with sulfide through periodic contraction into the anoxic and sulfidic diffusive boundary layer (DBL). Studies of the physical and chemical microenvironment around the colonies (Vopel et al. 2001, 2002, 2005) could not confirm this mechanism, but suggested that the feeding currents intercept sulfide and brings it to the symbiotic bacteria.

In this study, we link the sulfide transport quantitatively from the turbulent water column, via the feeding current, to the bacteria on the surface of $Z$. niveum. We analyze the flow field around individual colonies at high resolution. These data identify the source, pathway and volume of seawater passing through the colonies. We use literature data on the oxygen consumption of $Z$. niveum to estimate the sulfide requirements of the consortia based on the stoichiometry of lithothropic growth by sulfide oxidation. The filtered seawater volume together with the sulfide requirement provides a rough estimate of the constraints on sulfide uptake by the ecto-symbionts on $Z$. niveum. We refined the constraints further using numerical modeling.

\section{Material and methods}

Field site and sampling

Experimental work was conducted on the island of Carrie Bow Cay, Belize, in April 2002, at the field station operated by the Caribbean Coral Reef Ecosystem program of the National Museum of Natural History (Washington, DC, USA). Fieldwork was done in the channel that separates the two islands of Twin Cays, in an area locally known as Batfish Point. Detailed description of Twin Cays and the tidal channels can be found in Rützler and Macintyre (1982) and Ott et al. (1998).

In situ observations and ciliate collection were performed while SCUBA diving along undercut peat banks at Batfish Point. Current speed and direction were measured by timing $10 \mathrm{~cm}$ displacements of natural particles in the seawater with a stopwatch. Typical currents were $5-20 \mathrm{~mm} \mathrm{~s}^{-1}$ measured $1-3 \mathrm{~cm}$ from the peat surface. Then the spots with ciliate colonies were cut out together with a $20 \times 20 \times 20 \mathrm{~cm}^{3}$ block of surrounding peat and placed in a closed container while still under water.

\section{Laboratory flow cell}

After transport to the laboratory, the fibrous peat blocks were trimmed to fit a glass flow-cell that accommodated a $45 \mathrm{~mm}$ thick $90 \times 150$-mm peat block. Care was taken to align the surface of the peat flush with the inflow and to place the blocks with the same orientation to the current as 
they were found in situ. Peat and ciliates were never exposed to air.

Water in the flow cell was re-circulated through an aerated container holding $7 \mathrm{~L}$ of seawater. At the entrance of the flow cell, seawater was passed through $50 \mathrm{~mm}$ of coarse filter-foam (blue EHEIM) to dissipate inflow turbulence. A similar foam block was placed downstream of the peat to prevent the flow from converging toward the outflow. The free-flow section between the foam blocks was $150 \mathrm{~mm}$ and the water depth during measurements $50 \mathrm{~mm}$. Free flow velocity was adjusted to $1 \mathrm{~cm} \mathrm{~s}^{-1}$ reproducing a setting within the velocity range measured in situ (see below). The entire system was allowed to reach equilibrium at $29^{\circ} \mathrm{C}$ and $190 \mu \mathrm{mol} \mathrm{O} \mathrm{L}^{-1}$ before measurements. These values were within the range observed in the habitat. All laboratory observations were performed within $18 \mathrm{~h}$ from the time of collection.

\section{Particle-tracking velocimetry}

The flow cell was mounted on a metal frame together with a video microscope (Navitar) with a digital CCD camera (PCO SensiCam). A high resolution $2 \times 1.5 \mathrm{~mm}$ image field was captured from $90 \mathrm{~mm}$ distance. The frame also carried a laser diode with optics (Lasiris LAS-670-30) that projected a $0.1 \mathrm{~mm}$ thick vertical light sheet aligned with the flow. Camera and laser were mounted on micromanipulators to allow precise control of the area imaged. The seawater in the experimental system was spiked with $10 \mu \mathrm{m}$ diameter neutrally buoyant, hollow inert glass spheres, resulting in a turbidity matching the seawater at Batfish Point. Ciliates close to the center of the flow cell were illuminated with the vertical laser sheet and imaged by the CCD camera together with the particles suspended in the flow.

The images were subjected to four exposures of $1 \mathrm{~ms}$ separated by $2 \mathrm{~ms}$ intervals. The short intervals between the sub-exposures could resolve the fast flow in the swash behind a contracting colony by measuring displacement of particles between the first and the last exposure in a single image. Image sequences were recorded at a frequency of $10 \mathrm{~s}^{-1}$. The slower background flow and feeding currents were resolved by multi-frame PTV: corresponding particles were identified in three consecutive images and the velocity calculated from the displacements. Each velocity field typically contained 500-1,000 independent vectors. The scattered vectors were calculated into sectional streak-lines in the chosen plane using Tecplot (Amtec Engineering).

Finite element modeling

Advective and diffusive sulfide transport around individual feeding micro zooids were calculated in COMSOL
Multiphysics (Stockholm), which can perform reactiondiffusion-advection calculations in an arbitrary geometry by dividing it into triangular finite elements. The flow around individual zooids was calculated from the "Incompressible Navier-Stokes" application mode from the "Earth Science Module". Solute dynamics was calculated in the "Convection and Diffusion" application mode based on the results of the Navier-Stokes solution. Geometry of the zooids was based on Bauer-Nebelsick et al. (1996a, b) and that of T. zoothamnicoli on Rinke et al. (2007). The density of the calculation mesh was adjusted to give adequate calculation speed and tested not to influence the model results. Time steps were controlled dynamically to assure numerical stability. The applied model of $Z$. niveum describes a single radial-symmetric zooid with surrounding seawater. The purpose of the model was to describe the flux to the bacteria on the ciliates surface. Three scenarios were modeled: (1) one micro-zooid with functional cilliary apparatus; (2) a hypothetical scenario with a single isolated micro-zooid without feeding current, and (3) a single bacterial symbiont suspended in stagnant water.

Boundary conditions for scenario 1 were radial symmetry around the center of the zooid and unrestricted flow through upstream and downstream boundaries. The outer radial boundary was set to zero drag to simulate the presence of neighboring zooids with similar flow fields. The action of the cilliary apparatus was simulated by imposing a velocity of $0.6 \mathrm{~mm} \mathrm{~s}^{-1}$ parallel to the cell surface at the edge of the oral surface of the zooid. The boundary conditions for sulfide concentration were $3 \mu \mathrm{mol} \mathrm{L}^{-1}$ at the upstream boundary, radial symmetry around the center of the zooid and symmetry at the outer radial boundary. The downstream boundary was modeled purely as convective flux. Sulfide uptake was simulated by setting the concentration to zero at the surface of the zooid, which results in maximum estimates.

Scenario 2 contains no flow. The boundaries were moved $1 \mathrm{~mm}$ away from the zooid and sulfide concentration at the boundary was set to $3 \mu \mathrm{mol} \mathrm{L} \mathrm{L}^{-1}$. Sulfide uptake was simulated by setting the concentration to zero at the surface of the zooid as in scenario 1. This accurately simulates an isolated zooid in an infinite seawater volume and was performed to separate the effect of the feeding current from the effect of zooid geometry. This approach neglects depletion of sulfide between the zooids and therefore gives a clear overestimation of the possible sulfide flux.

Boundary conditions for scenario 3 : This scenario is a simple situation with a non-motile bacterial cell suspended in seawater. The modeled geometry was a $2 \mu \mathrm{m}$ long and $1 \mu \mathrm{m}$ thick rod-shaped bacterial cell in the centre of a $100 \mu \mathrm{m}$ sphere of water. Sulfide uptake was simulated by setting the concentration to zero at the surface of the bacterium and the infinite pool of sulfide in the water outside the 
modeled water sphere was simulated by setting the concentration on the outer boundary to $3 \mu \mathrm{mol}$ sulfide $\mathrm{L}^{-1}$. This scenario contains no flow.

Other parameters used in the models were a diffusion coefficient for sulfide $\left(2.23 \times 10^{-9} \mathrm{~m}^{-2} \mathrm{~s}^{-1}\right)$ and dynamic viscosity $\left(10^{-3} \mathrm{~Pa} \mathrm{~s}\right)$. The morphology of the micro-zooid was taken from Bauer-Nebelsick et al. (1996b) and the dimensions of the bacterial symbionts from Rinke et al. 2007. Flow velocity through the ciliary apparatus $\left(0.6 \mathrm{~mm} \mathrm{~s}^{-1}\right)$ was taken from the flow measurements. The sulfide concentration of $3 \mu \mathrm{mol}$ sulfide $\mathrm{L}^{-1}$ is where Rinke et al. (2007) found optimal growth. This external concentration is well within the range measured between the colonies in situ by Vopel et al. (2005).

\section{Results}

In situ observations and peat description

The peat structure was fibrous with occasional clumps of carbonate clay. Permeability of the clean peat calculated from percolation under a constant hydraulic head of $1,500 \mathrm{~Pa}$ (Klute and Dirksen 1986), was $4.6 \times 10^{-12} \mathrm{~m}^{-2}$ (SE $\left.1.9 \times 10^{-12}, n=15\right)$. It corresponds to the permeability of fine sand (Huettel and Gust 1992). All colonies examined grew at the mouth of a bark-lined tube that reached at least $5 \mathrm{~cm}$ into the peat. The diameters of the holes were between 5 and $10 \mathrm{~mm}$, but due to a fluffy overgrowth by root-fibers and microbial mats the opening was not always visible on the surface. Flows into, or out of, the bark channels were not apparent. Note, however, that at the concentration of sulfide in these channels is so high (Vopel et al. 2005) that even minute flows could supply enough substrate to drive a small thiotrophic community. $Z$. niveum grew attached to the exposed edges of the bark and to the peat within a distance of a few millimeters of the channel opening. White filamentous bacteria and pillows of filamentous sulfur were often found together with $Z$. niveum, but the ciliates were not generally found attached to areas covered by such mats.

Z. niveum colonies in situ contracted spontaneously at an average frequency of $1.7 \mathrm{~min}^{-1}$ (133 contractions observed in $78 \mathrm{~min}$, distributed over 24 different colonies). Similar frequencies were observed in the laboratory. No correlation could be found between the concentration of suspended particles and contraction frequency. The time between contraction and restarting of cilliary motion varied from 2 to $5 \mathrm{~s}$. Thus, the colonies spent $90 \%$ of the time fully stretched, with beating cilia.

Current velocity along the peat walls varied between 5 and $20 \mathrm{~mm} \mathrm{~s}^{-1}$, measured $10-30 \mathrm{~mm}$ from the peat surface. Velocities encountered by the ciliates on the peat surface

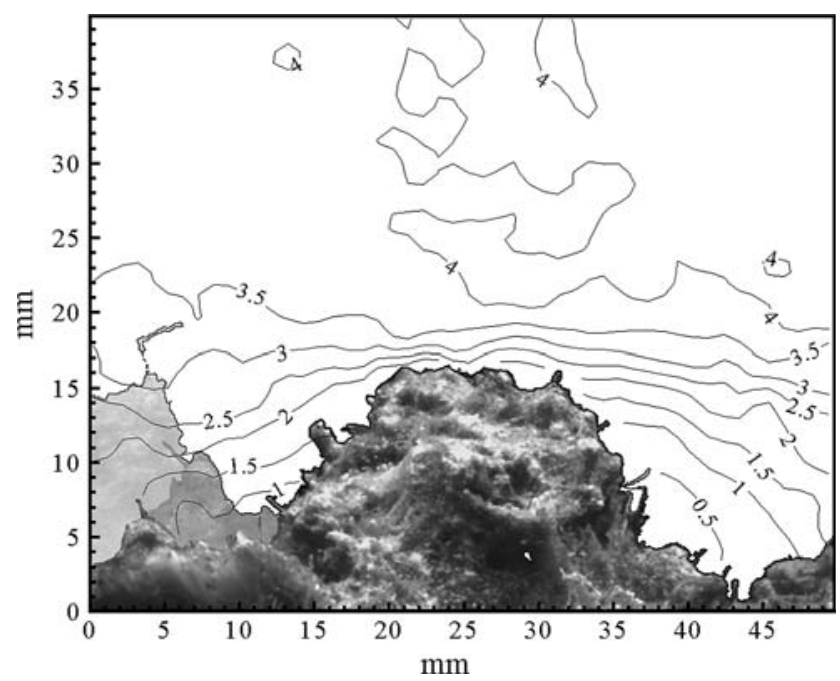

Fig. 2 Background flow along the rough peat surface. The flow, coming from the left, is visualized with isolines of equal flow speed. Note that these lines do not contain information about the flow direction. A Zoothamnium niveum colony on the lee side of the "hill" at $x=35 \mathrm{~mm}$, $y=10 \mathrm{~mm}$, can be seen close up in Fig. 3

depended on both the free-stream velocity and the local topography (Fig. 2). As in all other graphs in this paper, the free-stream was from left to right. Z. niveum grew attached to top and sides of the "hill" in the center of Fig. 2 that contained the empty bark of a mangrove root. Most individuals were found on the sides of the hill where flow was reduced.

Flow patterns during feeding

Three different current systems could be distinguished around feeding $Z$. niveum: (1) The feeding current, which is generated by the cilia of the zooids; (2) the secondary flow, which is induced by the feeding current but does not come into contact with the colony, and (3) the background current over the peat surface. Transitions between these current systems are smooth due to the prominence of viscous forces at low Reynolds numbers (Fig. 3a, b). The ambient current transforms smoothly into the feeding current, which passes through the colony along its entire length. The secondary current is seen as a vortex at the tip of the colony.

The feeding current was unidirectional through the colony from the convex side towards the concave (Fig. 3a). This seawater was ejected in a narrow band along the center-line of the colony. Velocity of the ejected seawater was always between 0.3 and $0.6 \mathrm{~mm} \mathrm{~s}^{-1}$, irrespective of colony size and background flow. At this velocity the water of the feeding current spent less than $1 \mathrm{~s}$ in the colony. The measured velocity in the feeding current was in the narrow range expected for membranelle-generated flow (Fenchel 1986). The Reynolds number, based on the length of the ejected jet, was around 1. Closed streak-lines (Fig. 3a) 

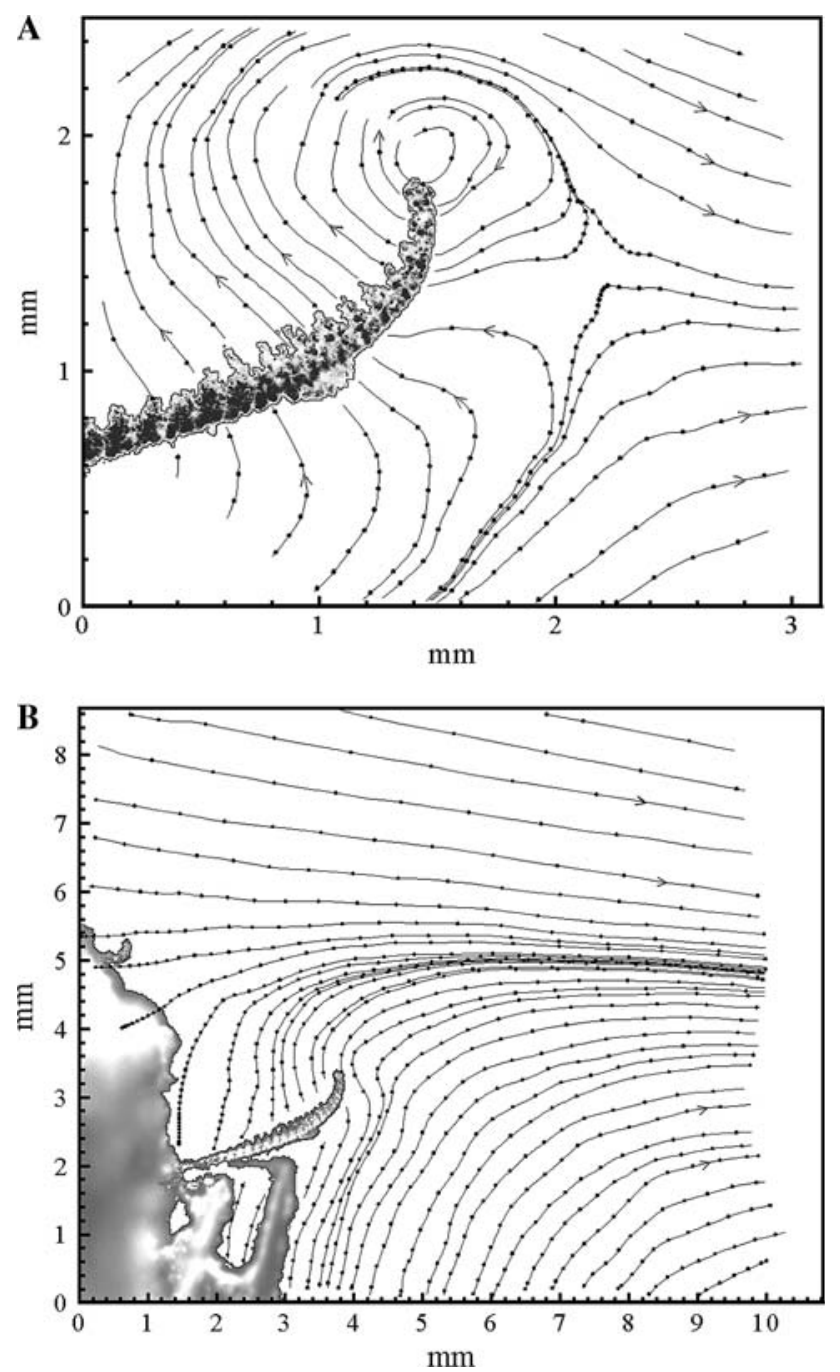

Fig. 3 a Flow field around a filtering Zoothamnium niveum in the backwater of a protruding bark channel. The same colony can be seen at $x=37 \mathrm{~mm}, y=8 \mathrm{~mm}$ in Figs. 2 and $3 \mathrm{~b}$. The streak lines show the direction of the momentary flow. As the pattern was quasi stable, suspended particles in the seawater roughly followed these lines. The dots on the streak-lines correspond to water displacement during $1 \mathrm{~s}$. Where the flow is diverging, as in the area around $x=2 \mathrm{~mm}, y=1 \mathrm{~mm}$, the flow in the depicted plane is replenished by an out-of-plane component. b Overview of the filtering Zoothamnium niveum also seen in Fig. 3a. The dots on the streak-lines corresponds to water displacement during $1 \mathrm{~s}$

could imply that the feeding current is re-circulated in the distal $0.3 \mathrm{~mm}$ of the colony, but following single particles ejected at the tip until they left the laser sheet revealed that this was not the case.

The secondary current formed a toroid along the perimeter of the colony. Flow along the edges was similar to the vortex at the tip of the colony in Fig. 3a, but moved in the plane out of the paper. Smaller secondary toroidal flows could occasionally be seen as rapidly circulating particles at the edge of individual zooids. The spatial resolution of the camera setup did not allow quantitative description of these.

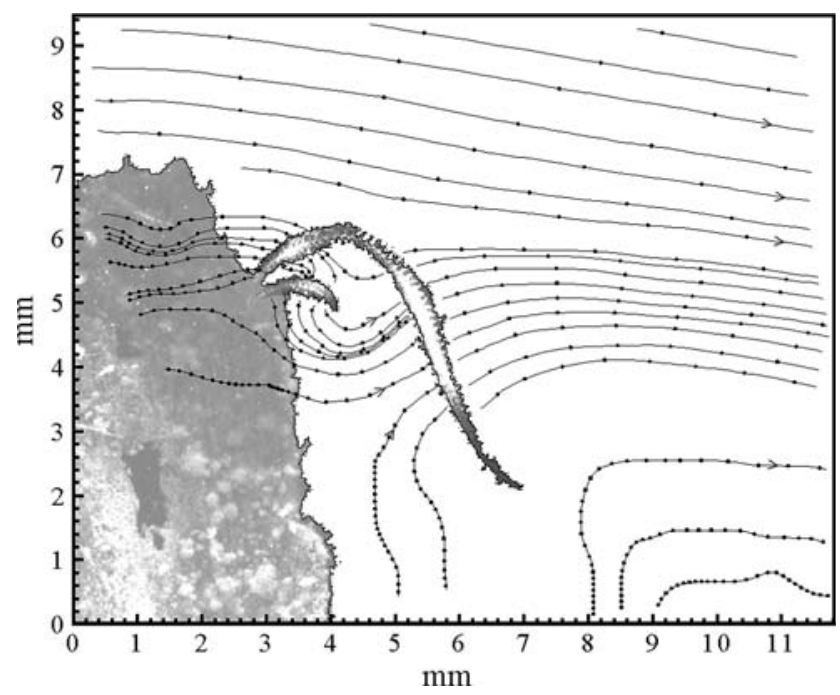

Fig. 4 Complex interactions between feeding currents of two Zoothamnium niveum colonies. The dots on the streak-lines corresponds to the water-displacement during $1 \mathrm{~s}$. See text for details

Colonies larger than $4 \mathrm{~mm}$ often had side branches and were more or less twisted. The general flow patterns described for smaller colonies remained, but with the complication that the feeding- and secondary currents between different parts of the colony interacted (Fig. 4). Here, seawater passed through the zooids at the base of a large colony and was directly picked up by a smaller colony. The ejected seawater from the smaller colony was then drawn through another part of the large colony again, as the large colony now took in seawater at the other side due to a $180^{\circ}$ twist. In situ, larger colonies were seen to bend back and forth in oscillating flow, which changed the orientation of the feeding currents continuously (see also Vopel et al. 2005).

\section{Quantification of feeding current}

Quantification of the flow through the colonies was complicated by the smooth transition between feeding current and secondary flow, but it can be constrained within narrow limits. A typical Z. niveum colony was $0.5 \mathrm{~mm}$ wide and $4 \mathrm{~mm}$ long, with the micro-zooids arranged in a single plane. It carried about 500 active microzooids, all on the outer $3 \mathrm{~mm}$ of the colony. Multiplying the 3 by $0.5 \mathrm{~mm}^{2}$ cross-sectional area with the velocity of the ejected current $\left(0.5 \mathrm{~mm} \mathrm{~s}^{-1}\right)$ suggests that a maximum $0.75 \mathrm{~mm}^{3}$ of seawater passes through the colony each second. A minimal estimate was calculated as follows: Particles expelled in a $0.1 \mathrm{~mm}$ wide band along the centerline had approximately the same velocity, but particles dimly illuminated by scattered light along the light sheet often moved slower. If only the $0.1 \mathrm{~mm}$ thick zone with consistent velocities is considered 
as the feeding current, then the seawater passed through the colony amounted to $0.15 \mathrm{~mm}^{3} \mathrm{~s}^{-1}$. The volume of 500 microzooids is $0.15 \mathrm{~mm}^{-3}$. Thus, the volume-specific filtration rate of the zooids was $1-5 \mathrm{~s}^{-1}$.

Flow patterns during ciliate contractions

Spontaneous contractions of $Z$. niveum were too fast to resolve with the camera used, but the fluid motion caused by the contractions could be followed (Fig. 5a). The ejected feeding current cannot be seen as it passed into the depicted plane. The colony was bending slightly away from the camera, so that the base of the colony was in the laser sheet, but the tip of the colony was behind it. A part of the secondary toroidal flow along the colony edges can therefore be seen as converging vectors around the colony. In the next image frame $0.1 \mathrm{~s}$ later the colony had contracted, leaving a swash of seawater in its wake (Fig. 5b). Note that the vector scale was reduced by one order of magnitude relative to Fig. 5a. The maximum velocity in Fig. $5 \mathrm{~b}$ was about $13 \mathrm{~mm} \mathrm{~s}^{-1}$, but velocities in excess of $30 \mathrm{~mm} \mathrm{~s}^{-1}$ were observed (data not shown). The seawater motion in the swash decayed almost to a standstill over the following $\sim 0.7 \mathrm{~s}$. The swash completely replaced the seawater around the contracted colony with seawater from above. The colony re-extended up through the decaying swash and, thus, into seawater reaching it from above rather than from the peat surface. During extension, the colony unfolded from the base upwards, and the zooids resumed cilliary pumping when the stretched position was achieved.

\section{Modeled flow and sulfide uptake}

The water volume forced directly by the cilia of the modeled zooid was $0.0004 \mathrm{~mm}^{3} \mathrm{~s}^{-1}$ while the total water volume transported was $0.0015 \mathrm{~mm}^{3} \mathrm{~s}^{-1}$. Volumes correspond to 0.21 and $0.75 \mathrm{~mm}^{3} \mathrm{~s}^{-1}$ for a colony with 500 zooids $\left(0.15-0.75 \mathrm{~mm}^{3} \mathrm{~s}^{-1}\right.$ was estimated from flow measurements). In both cases, the difference between the low and high estimate was due to inclusion of various amounts of secondary flow at the border of the feeding current (Fig. 6). Note that this part of the secondary flow contributed to the sulfide flux because of molecular diffusion towards the depleted feeding current. The resulting sulfide flux to the zooid is presented in Fig. 7. The vertical axis represents distance along the surface of the zooid from the base towards the centre of the oral surface. The starting point coincides with the lower boundary of Fig. 6 , i.e. on the stalk $3 \mu \mathrm{m}$ below the base of the zooid. In essence, the vertical axis could be wrapped around the perimeter of the zooid in Fig. 6. The flux-peak at $65 \mu \mathrm{m}$ occurred at the edge of the oral surface. The sulfide uptake in Fig. 7, integrated across the surface of a feeding micro-zooid (scenario 1), is
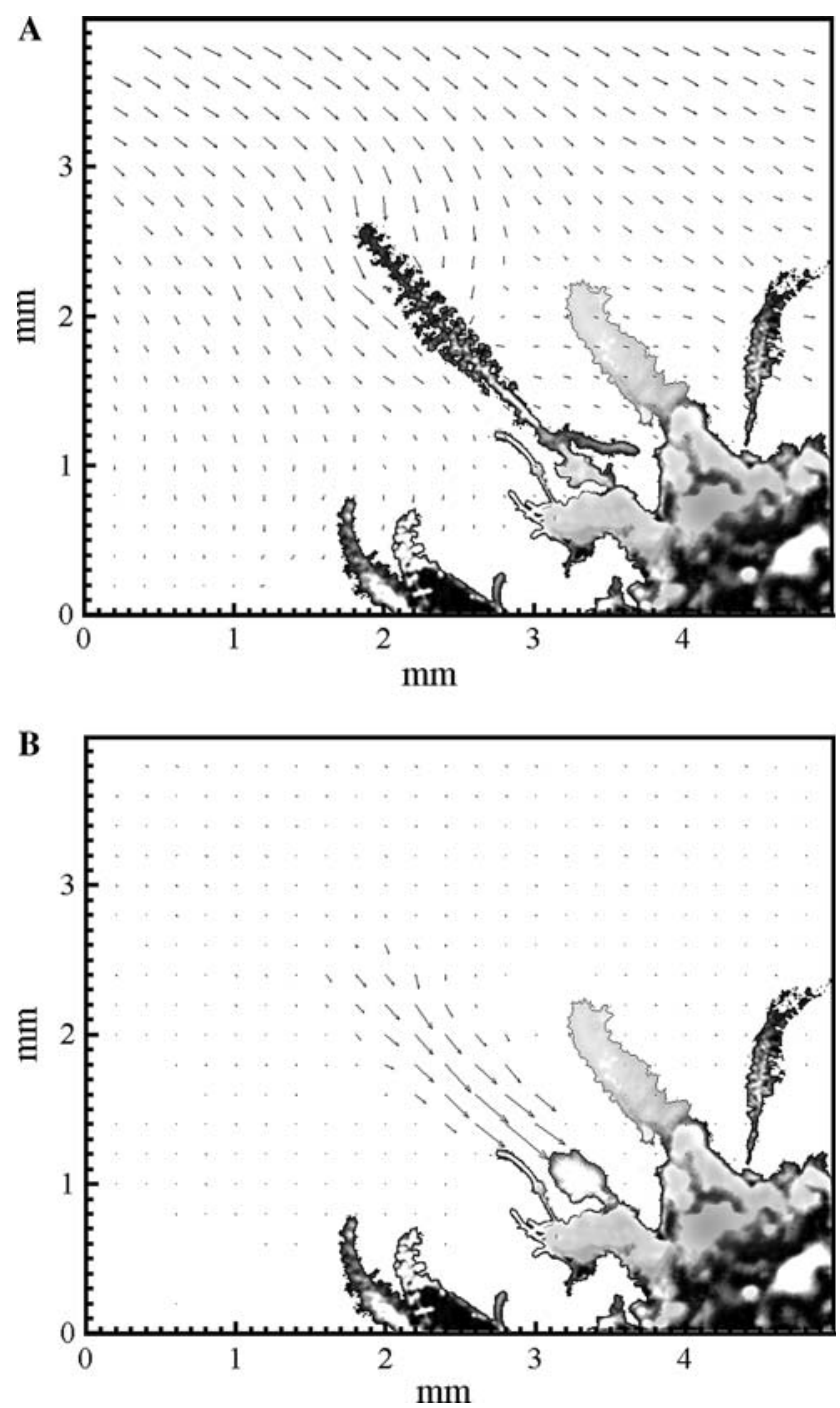

Fig. 5 a Flow field around a Zoothamnium niveum immediately before a contraction. Several non-contracting colonies are also seen. The vectors correspond to the seawater displacement during $0.25 \mathrm{~s}$. b The flow field around a $Z$. niveum within $100 \mathrm{~ms}$ after a contraction. The vectors correspond to the seawater displacement during $0.025 \mathrm{~s}$, one tenth of the vector length in Fig. 5b. The field of view is the same as seen in Fig. 4, which was recorded $0.1 \mathrm{~s}$ before. The contracted colony can be seen at $x=3.5 \mathrm{~mm}, y=1 \mathrm{~mm}$

$2.0 \times 10^{-15} \mathrm{~mol} \mathrm{~s}^{-1}$, while the hypothetical situation without flow yields a total uptake of $1.1 \times 10^{-15} \mathrm{~mol} \mathrm{~s}^{-1}$. The cell specific sulfide uptake rate of $T$. zoothamnicoli in the two scenarios was $3.9 \times 10^{-18}$ and $2.0 \times 10^{-18} \mathrm{~mol} \mathrm{~s}^{-1}$ respectively, based on the fluxes on the distal $15 \mu \mathrm{m}$ of the zooid and the "foot print" of the bacteria. To compare, the cell specific flux to the suspended bacterium was $38 \times 10^{-18} \mathrm{~mol} \mathrm{~s}^{-1}$ (model scenario 3 , geometry not shown). The maximum sulfide flux to a monolayer of bacteria on a planar surface under the same conditions as in the models can be calculated directly from the concentration in the seawater column and the thickness of the DBL. The planar DBL in marine environments ranges from 0.2 to $1.2 \mathrm{~mm}$ and is usually 


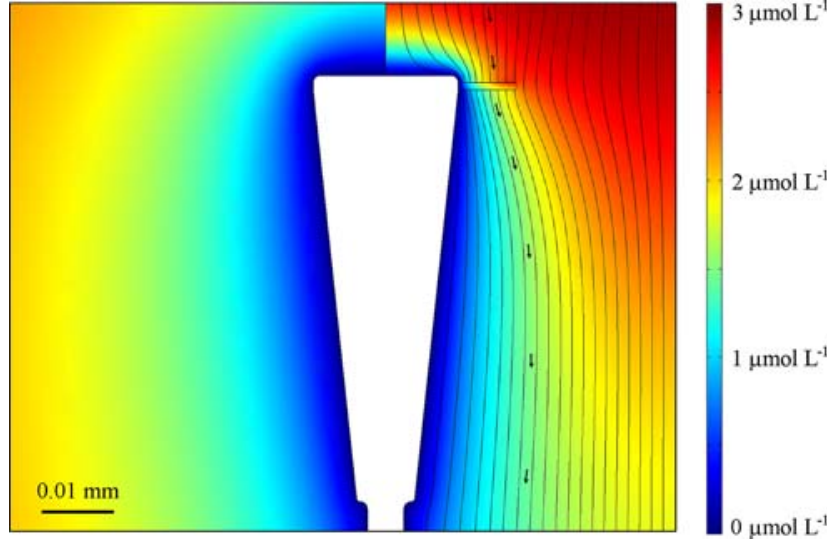

Fig. 6 Modeled sulfide concentration around a filtering (right half with streamlines) and a hypothetical non-filtering (left half) Zoothamnium niveum microzooid. The area where the flow was forced to $0.6 \mathrm{~mm} \mathrm{~s}^{-1}$ to simulate the cilia-generated current is marked by a box next to the zooid. Arrows indicate flow direction. The distance from the centerline to the right perimeter indicate the width of the domain modeled with flow while all other dimensions of the graph only shows a subsection of the modeled area

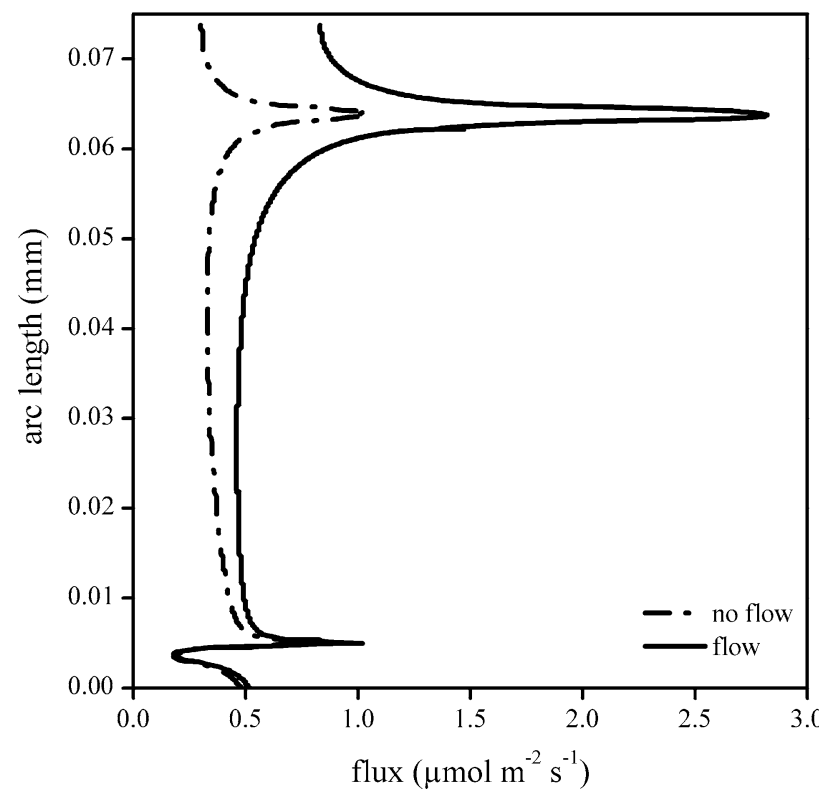

Fig. 7 Flux to the surface of a Zoothamnium niveum microzooid. The vertical axis in Fig. 7 represents distance along the surface of the protist from the base towards the center of the oral surface. The broken line represents the hypothetical non-filtering situation

close to $0.5 \mathrm{~mm}$ (Jørgensen 2001). This gives a maximum sulfide flux of $0.01 \mu \mathrm{mol} \mathrm{m} \mathrm{m}^{-2} \mathrm{~s}^{-1}$, corresponding to $0.013 \times 10^{-18} \mathrm{~mol} \mathrm{~s}^{-1}$ per cell the size of $T$. zoothamnicoli, if the bacteria cover the surface in a single layer.

\section{Sulfur budget of $Z$. niveum}

There are no published data on sulfide assimilation rates of the $Z$. niveum symbiosis. But the sulfur budget can be cal- culated from oxygen consumption rates published by Ott et al. (1998). These authors measured the oxygen flux to freshly collected $Z$. niveum in non-sulfidic medium to be 460 (SD 40) $\mathrm{nL} \mathrm{O}_{2} \mathrm{~mm}^{-2}$ of ciliate surface per hour (original units). The flux decreased to 140 (SD 16) $\mathrm{nL} \mathrm{O}_{2} \mathrm{~mm}^{-2} \mathrm{~h}^{-1}$ over $20 \mathrm{~h}$, after which it remained stable. The time span over which the flux decreased corresponds to the time it takes $Z$. niveum to change from white to translucent when removed from its natural environment. We therefore assume that the difference between the initial flux and the stable flux can be attributed to oxidation of the sulfur globules in the symbionts. This assumption is supported by the observation of Ott et al. (1998), that a high flux could be re-established through incubation in sulfidic medium. As calculated from the difference between initial and stable flux and transferred to SI units, the oxygen flux going to sulfur oxidation is 3.97 ( $\mathrm{SD} 0.53) \mu \mathrm{mol} \mathrm{m} \mathrm{m}^{-2} \mathrm{~s}^{-1}$.

The oxidation of $2 \mathrm{~mol}$ of elemental sulfur to sulfuric acid requires $3 \mathrm{~mol}$ of $\mathrm{O}_{2}$. By applying this stoichiometric relation to the $\mathrm{O}_{2}$ flux, we get the initial rate of sulfur oxidation: $2.64 \mu \mathrm{mol} \mathrm{m}{ }^{-2} \mathrm{~s}^{-1}$. As the elemental sulfur only acts as an intermediate storage compound, the oxidation of $\mathrm{S}^{0}$ must be coupled 1:1 to uptake and partial oxidation of $\Sigma \mathrm{H}_{2} \mathrm{~S}$ during normal growth conditions. One molecule of $\mathrm{O}_{2}$ is required to oxidize two molecules of hydrogen sulfide to elemental sulfur, and this amount must be added to the $3.97 \mu \mathrm{mol} \mathrm{O} \mathrm{O}_{2} \mathrm{~m}^{-2} \mathrm{~s}^{-1}$, raising the $\mathrm{O}_{2}$ flux required for sulfur oxidation to $6.61 \mu \mathrm{mol} \mathrm{m} \mathrm{m}^{-2} \mathrm{~s}^{-1}$. During chemoautotrophic growth, a part of the electrons assimilated from hydrogen sulfide are channeled into carbon fixation and thereby are not reflected in the $\mathrm{O}_{2}$ budget. In Beggiatoa this amounts to $20 \%$ of the electrons used for energy conservation (Nelson et al. 1986). Applying the same growth efficiency on the symbionts on $Z$. niveum, we must add $20 \%$ to the $\Sigma \mathrm{H}_{2} \mathrm{~S}$ flux calculated from the $\mathrm{O}_{2}$ flux. Summing up, the bacteria on the surfaces of the $Z$. niveum for which Ott et al. (1998) measured the $\mathrm{O}_{2}$ consumption must have sustained a $\Sigma \mathrm{H}_{2} \mathrm{~S}$ flux of 3.19 (SD 0.42) $\mu \mathrm{mol} \mathrm{m}^{-2} \mathrm{~s}^{-1}$ and an $\mathrm{O}_{2}$ flux of 6.61 (SD 0.88$) \mu \mathrm{mol} \mathrm{m} \mathrm{m}^{-2} \mathrm{~s}^{-1}$ to be in steady state with respect to stored elemental sulfur. Compare this to the modeled flux in Fig. 7.

We consider a $4 \mathrm{~mm}$ tall $Z$. niveum colony with 50 side branches carrying a total of 500 microzooids as a standard colony, and that a typical white spot of $1 \mathrm{~cm}^{2}$ contains 26 such colonies (Ott et al. 1998). According to the dimensions of the zooids given by Bauer-Nebelsick et al. (1996b), the surface area of one colony was about $2.5 \times 10^{-6} \mathrm{~m}^{2}$. Thus, the total sulfide oxidation of all $Z$. niveum within one spot was $2.07 \times 10^{-10} \mathrm{~mol}$ sulfide $\mathrm{s}^{-1}$, or $2.07 \mu \mathrm{mol}$ sulfide $\mathrm{m}^{-2} \mathrm{~s}^{-1}$ for the area of the white spot. This is above the maximum sustainable flux to a Beggiatoa mat that is constrained by oxygen diffusion through the $0.2-1.2 \mathrm{~mm}$ thick DBL (Jørgensen 2001). 


\section{Discussion}

\section{Sulfide assimilation by Z. niveum}

Ott et al. (1998) suggested that the swarmers (dispersion stage) of $Z$. niveum preferentially settle where the microbial mat leaks hydrogen sulfide. The attached swarmer has a diameter around $100 \mu \mathrm{m}$, and will be completely submerged in the DBL. It develops into young colonies in about 4 days. During this period, the parts of the colony that carry the ecto-symbionts will grow into the mixed seawater column. One way to explain the continued growth on sulfide oxidation as the colony grows away from the peat surface is periodic contraction into a sulfidic boundary layer as proposed by (Ott et al. 1998). As seen in Fig. 5b, however, the rapid contraction of a $Z$. niveum colony generates a swash of seawater towards the base area of the ciliate. This result confirms the observations of Vopel et al. (2001), that a contraction is followed by an increase in oxygen concentration at the base of the colony. Due to inertia, the fluid motion initiated by the contraction persists for a while after the driving force has vanished. As a result, the seawater surrounding the contracted colony is fully oxygenated seawater directly from the seawater column. During the following slower extension, most of the seawater that follows the colony back up has therefore spend less than one-second at the peat surface. The model proposed by Ott et al. (1998) suggested that more seawater should adhere to the colony when extending than during contraction. In this respect our measurements showed the opposite. This is explained by basic hydrodynamic principles: The drag on objects moved through a fluid at high velocities is proportional to the velocity squared. Therefore, more seawater is transported inwards via the fast contraction than what is drawn back out with the slow expansion of the $Z$. niveum colonies. Once back in the mixed seawater column, the resumption of cilliary pumping ejects the seawater from the colony. Thus, the exposure to seawater from the water layer near the peat surface is limited and the contractions do not supply sulfide via the mechanism proposed by Ott et al. (1998).

Sulfide dispersing from the bark conduits into the seawater column is a more likely source than a sulfidic boundary layer below the $Z$. niveum colonies. The gentle surge from surface waves results in an unstable mixture of fully oxygenated and sulfide-containing seawater in front of the conduit opening (Vopel et al. 2005). Turbulent mixing and advective transport will be controlling the concentration and distribution of sulfide, as these mechanisms will remove solutes much faster than the slow abiotic reaction between sulfide and $\mathrm{O}_{2}$ (Zhang and Millero 1994; Visser et al. 1997; Zopfi et al. 2001). Turbulent diffusion is rapid in open water. We should therefore expect the sulfide concentration to drop very fast with increasing distance from the conduit opening, which is consistent with the sharp limits of the white spots. We propose that $Z$. niveum extracts the sulfide necessary to sustain the symbiosis from the mixture of small amounts of sulfidic water from the mouth of the bark conduits and air-saturated seawater. This view of the $Z$. niveum niche on the peat banks of Belizean barrier islands resembles the conditions in locations on Corsica, France, where it recently has been found. Here it lives attached to rock surfaces in the vicinity of decaying sea grass (Rinke et al. 2007). Micro-molar concentration of sulfide in norm-oxic seawater is also the medium in which $Z$. niveum has been successfully cultivated.

If the symbiotic bacteria on $Z$. niveum were growing on a two-dimensional surface instead of on a ciliate, then the maximum sulfide uptake rate would be about $1 \%$ of that calculated from the oxygen consumption rates and from the numerical model (see calculations above). This is possible because the dynamics of seawater motion over the surfaces of a zooid are drastically different than seawater moving over a microbial mat on a two-dimensional surface. At the zooid surface, the seawater motion is drawn from the surface via the cilliary motion, while the flow is retarded by friction with the seawater at further distance from the colony. In effect, it is a boundary layer turned inside out. Thus, the surface of the zooid comes in close contact with seawater carrying solutes at the concentration of the bulk seawater (Fig. 6, right). The modeled flux to the zooid surface (Fig. 7) is a conservative estimate since it is modeled without taking into account the ciliary activity on the oral surface. Nevertheless, there is agreement between the average flux in Fig. 7 and the flux calculated from oxygen consumption (3.19 $\left.\mu \mathrm{mol} \mathrm{m}^{-2} \mathrm{~s}^{-1}\right)$. By comparing the modeled flux with and without feeding current (Fig. 7), it appears that that a large part of the enhanced flux to the zooid can be explained by the slender radial geometry rather than to the feeding current, since the scenario modeled with active pumping is only twice as high as to passive diffusion. The purely diffusive calculation is, however, clearly an overestimation since it neglects competition for sulfide between neighboring microzooids. Thus, the main mechanism behind the high sulfide flux is the feeding current. The highest sulfide flux occurs near the ciliature, and this corresponds to the pattern of systematically large bacterial symbionts found on the oral parts of the zooids by Rinke et al. (2007).

The maximum sulfide uptake by suspended bacteria is still one order of magnitude higher than what is possible on the surface of $Z$. niveum. Thus, there would be a theoretical gain for the bacteria in pelagic life, but at an obvious disadvantage when relying on a point source of substrate located in a wave-swept environment. 


\section{Conclusions}

The surfaces of $Z$. niveum are a much more favorable habitat for sulfide-oxidizing bacteria than a two-dimensional surface, when sulfide and oxygen coexist in the seawater around the colonies. Considering the consortia of $Z$. niveum with its ectosymbionts as specialized in acquiring low concentrations of sulfide from the seawater column agrees well with its occurrence on stones and vertical rocks adjacent to decomposing sea grass in the Mediterranean. Diffusive supply of sulfide from below can be excluded when the substrate is stone. But when thick layers of sea grass decompose in a wave-swept environment, it is likely that small amounts of $\mathrm{H}_{2} \mathrm{~S}$ are present in the seawater column. It is interesting to note that the larger the ciliate colony grows, the better it will come in contact with the seawater column. Any influence the bacteria have that increases the size of the ciliate colony will thereby be beneficial to bacteria depending on solutes from the seawater column. This sets a likely scenario for the evolution of a trophic symbiosis, as well as giving a possible explanation for the large size of the $Z$. niveum relative to other ciliates. The feature that makes the surfaces of $Z$. niveum a lucrative habitat for sulfide-oxidizing bacteria is the feeding current. So rather than being a special case, exploiting sharp, crossing gradients of sulfide and $\mathrm{O}_{2}, \mathrm{Z}$. niveum is more likely functionally equivalent to metazoans carrying symbionts in filtering organs such as the clams and tube worms of hydrothermal fields (e.g., Cavanaugh 1994).

Acknowledgments This work was supported by the Caribbean Coral Reef Ecosystems program of the Smithsonian National Museum of Natural History (Washington, DC), the Danish Research Academy and the Max Plank Society. We thank J. Ott for introducing us to the study $Z$. niveum, and M. Carpenter and D. Miller for support on Carrie Bow Cay. The manuscript was greatly improved by constructive reviews. This is contribution 658, Caribbean Coral Reef Ecosystems Program, Smithsonian Institution. The experiments comply with the current laws of Belize and Germany.

Open Access This article is distributed under the terms of the Creative Commons Attribution Noncommercial License which permits any noncommercial use, distribution, and reproduction in any medium, provided the original author(s) and source are credited.

\section{References}

Bauer-Nebelsick M, Bardele CF, Ott JA (1996a) Electron microscopic studies on Zoothamnium niveum (Hemprich \& Ehrenberg, 1831) Ehrenberg 1838 (Oligohymenophora, Peritrichida), a ciliate with ectosymbiotic, chemoautotrophic bacteria. Eur J Protistol 32:202-215

Bauer-Nebelsick M, Bardele CF, Ott JA (1996b) Redescription of Zoothamnium niveum (Hemprich \& Ehrenberg, 1831) Ehrenberg, 1838 (Oligohymenophora, Peritrichida), a ciliate with ectosymbiotic, chemoautotrophic bacteria. Eur J Protistol 32:18-30

Cavanaugh CM (1994) Microbial symbiosis-patterns of diversity in the marine-environment. Am Zool 34:79-89

Fenchel T (1986) Protozoan filter feeding. Prog Protistol 1:65-113

Huettel M, Gust G (1992) Solute release mechanisms from confined sediment cores in stirred Benthic Chambers and Flume Flows. Mar Ecol Prog Ser 82:187-197. doi:10.3354/meps082187

Jørgensen BB (2001) Life in the diffusive boundary layer. In: Boudreau BP, Jørgensen BB (eds) The benthic boundary layer: transport processes and biogeochemistry. Oxford University Press, New York, pp 348-373

Klute A, Dirksen C (1986) Hydraulic conductivity and diffusivity: laboratory methods. In: Klute A (ed) Methods of soil analysis-part 1--physical and mineralogical methods. Am Soc Agron, Madison

Nelson DC, Jørgensen BB, Revsbech NP (1986) Growth-pattern and yield of a chemoautotrophic Beggiatoa sp in oxygen-sulfide microgradients. Appl Environ Microbiol 52:225-233

Ott JA, Bright M, Schiemer F (1998) The ecology of a novel symbiosis between a marine peritrich ciliate and chemoautotrophic bacteria. Mar Ecol-Pubbl Stn Zool Napoli 19:229-243

Rinke C, Schmitz-Esser S, Stoecker K, Nussbaumer AD, Molnar DA, Vanura K, Wagner M, Horn M, Ott JA, Bright M (2007) "Candidatus thiobios zoothamnicoli" an ectosymbiotic bacterium covering the giant marine ciliate Zoothamnium niveum. Appl Environ Microbiol 72:2014-2021. doi:10.1128/AEM.72.3.20142021.2006

Rützler K, Macintyre IG (1982) The habitat distribution and community structure of the barrier reef complex at Carrie Bow cay, Belize. In: Rützler K, Macintyre IG (eds) The Atlantic barrier reef ecosystems at Carrie Bow Cay, Belize, I: structure and communities. Smithsonian Institution Press, Washington, pp 9-45

Visser JM, Robertson LA, VanVerseveld HW, Kuenen JG (1997) A novel membrane-bound flavocytochrome $\mathrm{C}$ sulfide dehydrogenase from the colourless sulfur bacterium Thiobacillus sp. W5. Arch Microbiol 167:295-301. doi:10.1007/s002030050447

Vopel K, Pöhn M, Sorgo A, Ott JA (2001) Ciliate-generated advective seawater transport supplies chemoautotrophic ectosymbionts. Mar Ecol Prog Ser 210:93-99. doi:10.3354/meps210093

Vopel K, Thistle D, Ott JA, Bright M, Røy H (2005) Wave-induced $\mathrm{H}_{2} \mathrm{~S}$ flux sustains a chemoautotrophic symbiosis. Limnol Oceanogr 50:128-133

Vopel K, Reick CH, Arlt G, Pöhn M, Ott JA (2002) Flow microenvironment of two marine peritrich ciliates with ectobiotic chemoautotrophic bacteria. Aquat Microb Ecol 29:19-28. doi:10.3354/ ame029019

Zhang JZ, Millero FJ (1994) Kinetics of oxidation of hydrogen sulfide in natural waters. In: Alpers CN, Blowes DW (eds) Environmental geochemistry of sulfide oxidation. Am Chem Soc, Washington, pp 393-409

Zopfi J, Ferdelman T, Jørgensen BB, Teske A, Thamdrup B (2001) Influence of water column dynamics on sulfide oxidation and other major biogeochemical processes in the chemocline of Mariager Fjord (Denmark). Mar Chem 74:29-51. doi:10.1016/ S0304-4203(00)00091-8 